\title{
Intelligent Based Image Enhancement using Direct and In-Direct Contrast Enhancement Techniques - A Comparative Survey
}

\author{
S. Supriya ${ }^{1}$ and M. Subaji ${ }^{2}$ \\ ${ }^{1}$ Department of Computer Science and Engineering, VIT University, Vellore - \\ 632014 \\ Tamil Nadu, India \\ ${ }^{2}$ Professor \& Deputy Director, Centre for Industry \& International Studies, VIT \\ University \\ Vellore - 632014, Tamil Nadu, India \\ ${ }^{1}$ supriya.is.s@gmail.com, ${ }^{2}$ msubaji@vit.ac.in
}

\begin{abstract}
The main goal of Image enhancement is to enhance the fine details present in the images having low luminance for better image quality. It can be classified into two categories namely: Direct Contrast Enhancement and In-Direct Contrast Enhancement. Histogram Equalization $(H E)$ is one of the most prominent In-Direct contrast enhancement technique used for contrast enhancement in digital image processing. More specifically, we categorize In-Direct contrast enhancement techniques based on the input histogram partitioning criteria. For some methods, separation/partition point is based on the mean-average or median intensity values. A comparative survey is carried out in this paper, explaining different Direct and In-Direct Contrast Enhancement techniques based on local and Global contrast measurements along with their advantages and disadvantages. Overall the paper contributes to classify and compare the filter based, Intelligent based, Fuzzy Logic based contrast enhancements among various available techniques described. Comparison using Linear index of fuzziness and Absolute Mean Brightness Error (AMBE) helps to evaluate an active research, significantly decide on a suitable algorithm and provide a promising direction towards future research on image enhancement.
\end{abstract}

Keywords: Image Enhancement, Histogram Equalization, Linear index of fuzziness, $A M B E$

\section{Introduction}

Over the last few decades, the visual image quality is improved with active research towards techniques enhancing the contrast of images, in various fields of interest such as medical imaging systems, digital photography, satellite imaging, underwater visibility imaging, vision and face recognition, video surveillance systems, radar image processing, virtual restoration of ancient Chinese painting, digital photography and sonar image processing and so on. Nowadays, a trend in using mobile phones for capturing pictures is well seen, but due to hardware limitation observed in mobile phones for digital photography, the image quality can vary based on its resolution, focus, light intensity, a sudden bright light change or a shadow effect etc., leading to poor image contrast with distortions and high noise levels. This is more specifically observed when dealing with videos (a rapid change from one image to another). When the input image is highly concentrated with contrast over a specific range, for example a very dark image, most of its information in those areas may be lost. Hence some post-processing is required to improve the visual quality of the captured image. One such is Contrast enhancement focusing on optimizing the contrast of the input image. The contrast enhancement 
techniques should address some basic features and properties like noise immunity/tolerance, uniform contrast and enhancing the fine details present in the image by modifying its intensity values, thus improving the visual quality of the image and preserving its mean brightness. Histogram Equalization (HE) [1] is one of the most popular Contrast Image Enhancement methods. Most of the Contrast Image Enhancement techniques listed in this paper have been implemented, with their results being published. The purpose of this paper is to have a comparative survey describing the underlying concepts of each technique based on their merits and demerits. All these Algorithms are intended to modify images in order to overcome their deficiencies leading to good looking/appealing visual quality images. But few of these algorithms may over enhance certain bright regions affecting the output. Filters are also used to enhance the images mainly to restore the image quality from noise. In some cases, frequency and Wavelet transforms are efficient ways of image enhancement for low light images. When considering frame-to-frame sequences - dealing with videos or low light images, a flicker effect is observed leading to rapid dynamic changes. To solve this problem, Dual tree complex wavelet transform is used instead of discrete wavelet transform [12]. Due to the usage of Contrast Limited Adaptive Histogram Equalization [52], tiling distortion observed in the output image. Most issues observed with these algorithms are related to image features used, cannot be easily constructed. Few other algorithms also involve Global and Local Histogram modification techniques [9]. The Global Histogram Modification technique operates on all pixels at the same instance of time and cannot adapt to the local brightness features. Some parts of the images are limited to contrast enhancement. On the other hand, the local histogram modification method leads to over enhancement, introducing noise-enhancing artifacts at some parts of the images. This helps the investigators in selecting a suitable enhancement technique based on their needs and resolves other issues observed while enhancing the images.

\section{Image Enhancement Issues}

Image Enhancements helps in improving the visual quality of the image as perceived by a human eye. He results in introducing noisy artifacts and intensity saturation effects. One of the disadvantages observed with HE process is an abrupt change in the output image due to the absence of numerous intensity values. It normally tends to change the mean brightness of the image, thus the resultant output image may be highly saturated with very dark or bright levels of intensities. Over enhancement is also one of the issues observed in the enhanced image. Some of the techniques described in this paper do not provide an effective level of adjustment while enhancing the processed image, often subjected to unnatural enhancement. Certain techniques assign new dynamic range (DR) to histogram peaks which significantly alter the mean brightness of the image. Also the enhancement should ensure the sum of weights of the given original image to be correct without any change to the pixel count when the histogram bins are clustered as large groups. Also extracting the feature edges plays an important role in object recognition while enhancing the image.

\section{In-Direct Contrast Enhancement}

In-Direct Contrast Enhancement method cannot manipulate the image contrast directly. It involves modifying the histogram of the image thus improving contrast. Histogram Equalization is one of the most prominent In-Direct contrast enhancement techniques. HE enhances the image by stretching the DR of gray levels and flattening the pixel density in order to improve the overall contrast of the image. One of the drawbacks observed in HE is the utilization of cumulative density function in transforming the gray levels of the original image to levels of enhanced image, which tends to distort the mean brightness of the image, resulting in introducing noisy artifacts and intensity saturation effects. Also 
multi HE divides the input histogram into segments using thresholds which are determined using the mean, median and variance of the input image histogram. Figure 1 shows the histogram graph of the Original Image. Few popular in-direct contrast enhancement methods are described below in Table 1 and 2.

In order to maintain and preserve mean brightness of the image [20] with natural appearance, the output image should have a unique evenly expanded intensity levels on each segment of the histogram - targeting the intensity saturation problems. The below Table1 describes each technique based on the traditional HE with a research focus and its limitations while arriving at a solution to Contrast Image enhancement issues.
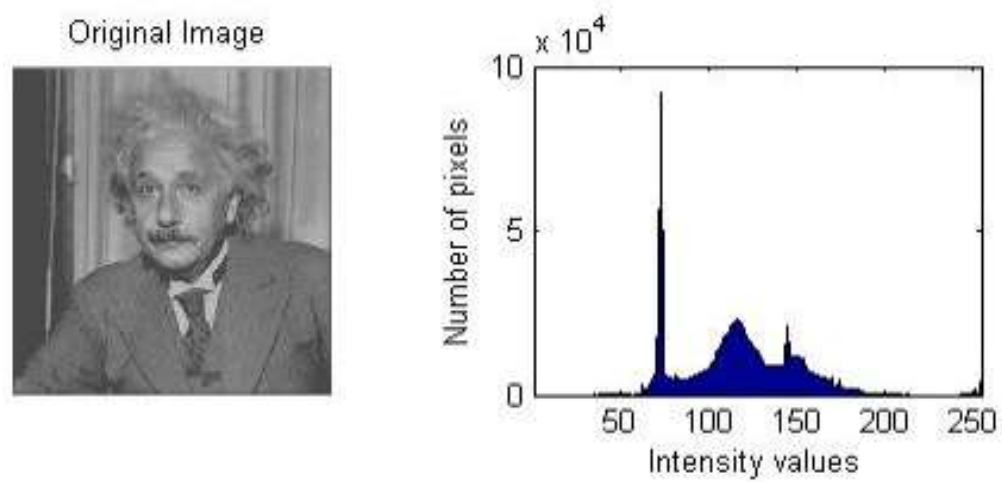

Figure 1. Histogram Graph of the Original Image

\section{Table 1. Describes Histogram Equalization Techniques Based on Input Histogram Separation Point}

\begin{tabular}{|c|c|c|c|}
\hline $\begin{array}{c}\text { Author and } \\
\text { Technique Used }\end{array}$ & Research Focus & Proposed Solution & Limitation \\
\hline $\begin{array}{l}\text { Simple histogram } \\
\text { modification } \\
\text { scheme (SHMS) [4] }\end{array}$ & $\begin{array}{l}\text { It modifies the input } \\
\text { histogram before HE. Best } \\
\text { suited for single threshold. }\end{array}$ & $\begin{array}{l}\text { Performs replacing the non- } \\
\text { zero bin in the input } \\
\text { histogram to the zero }{ }^{\text {th }} \text { bin and } \\
\text { then the last non-zero bin is } \\
\text { replaced with minimum bin } \\
\text { between the last two non-zero } \\
\text { bins }\end{array}$ & $\begin{array}{l}\text { With multiple } \\
\text { thresholds, SHMS } \\
\text { limits the brightness } \\
\text { resulting in annoying } \\
\text { artifacts }\end{array}$ \\
\hline $\begin{array}{l}\text { Modified } \\
\text { Histogram } \\
\text { Equalization } \\
\text { (MHE) [9] }\end{array}$ & 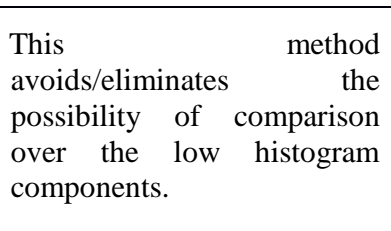 & $\begin{array}{l}\text { It modifies the input } \\
\text { histogram using a } \\
\text { modification operation by } \\
\text { reducing the accumulation of } \\
\text { the higher histogram bins } \\
\text { before applying the HE. }\end{array}$ & $\begin{array}{l}\text { Leads to domination } \\
\text { effect. Fine details } \\
\text { are missed out. }\end{array}$ \\
\hline $\begin{array}{l}\text { Brightness } \\
\text { Preserving } \\
\text { Dynamic Fuzzy } \\
\text { Histogram } \\
\text { Equalization } \\
\text { (BPDFHQ) [12] }\end{array}$ & $\begin{array}{l}\text { An extension to BPDHE } \\
\text { [60]. Significantly used for } \\
\text { high peak histogram images } \\
\text { and preserves brightness. }\end{array}$ & $\begin{array}{l}\text { It uses Fuzzy statistics for } \\
\text { smoothing the histogram } \\
\text { before performing the } \\
\text { segmentation of the input } \\
\text { histogram. }\end{array}$ & $\begin{array}{l}\text { High Computational } \\
\text { cost involved with } \\
\text { BPDHE }\end{array}$ \\
\hline $\begin{array}{l}\text { Adaptive histogram } \\
\text { based Algorithm } \\
\text { (AHEA) [13] }\end{array}$ & $\begin{array}{l}\text { Introduces a } \beta \text { parameter in } \\
\text { the gray level mapping } \\
\text { formula. It avoids excessive } \\
\text { gray levels and bright } \\
\text { regions. }\end{array}$ & $\begin{array}{l}\text { The spacing between the two } \\
\text { adjacent gray levels is } \\
\text { adaptively adjusted - by } \\
\text { taking the entropy data as a } \\
\text { target function. }\end{array}$ & $\begin{array}{l}\text { Holds good only for } \\
\text { CT image processing } \\
\text { in medicine. }\end{array}$ \\
\hline $\begin{array}{l}\text { Background } \\
\text { Brightness }\end{array}$ & $\begin{array}{l}\text { Separates the input image } \\
\text { based on background levels }\end{array}$ & $\begin{array}{l}\text { After separation, } \\
\text { individual sub parts are }\end{array}$ & $\begin{array}{l}\text { Quality of the image } \\
\text { is not good when }\end{array}$ \\
\hline
\end{tabular}




\begin{tabular}{|c|c|c|c|}
\hline $\begin{array}{c}\text { Author and } \\
\text { Technique Used }\end{array}$ & Research Focus & Proposed Solution & Limitation \\
\hline $\begin{array}{l}\text { Preserving } \\
\text { Histogram } \\
\text { Equalization } \\
\text { (BBPHE) [14] }\end{array}$ & $\begin{array}{l}\text { and non-background levels. } \\
\text { Excessive enhancements are } \\
\text { avoided in BBPHE. }\end{array}$ & $\begin{array}{l}\text { further equalized and } \\
\text { combined to form final output } \\
\text { histogram. }\end{array}$ & $\begin{array}{l}\text { compared to other } \\
\text { techniques }\end{array}$ \\
\hline $\begin{array}{l}\text { A new Adaptive } \\
\text { Contrast } \\
\text { Enhancement using } \\
\text { DRSHE (Dynamic } \\
\text { Recursive } \\
\text { separation } \\
\text { Histogram } \\
\text { Equalization) [15] }\end{array}$ & $\begin{array}{l}\text { Input image is partitioned } \\
\text { into several blocks and each } \\
\text { block is applied with } \\
\text { DRSHE [61]. Only the } \\
\text { luminance values Y are } \\
\text { processed. }\end{array}$ & $\begin{array}{l}\text { DR in each block is obtained } \\
\text { and divided into K parts. Area } \\
\text { ratio of the } \mathrm{K}^{\mathrm{th}} \text { segment is } \\
\text { calculated and DR is } \\
\text { expanded by a factor L. The } \\
\mathrm{K}^{\text {th }} \mathrm{DR} \text { is resized and applied } \\
\text { to each portion. }\end{array}$ & $\begin{array}{lr}\text { Block noise is } \\
\text { introduced among } \\
\text { neighboring } \quad 4 \\
\text { blocks. Applied to } \\
\text { only flat area images }\end{array}$ \\
\hline $\begin{array}{l}\text { Adaptive Gamma } \\
\text { Correction with } \\
\text { Weighting } \\
\text { Distribution } \\
\text { (AGCWD) [20] }\end{array}$ & $\begin{array}{l}\text { Uses temporal differences } \\
\text { information between each } \\
\text { frame - to reduce } \\
\text { computational complexity. }\end{array}$ & $\begin{array}{l}\text { Using Gamma correction, the } \\
\text { brightness values of dimmed } \\
\text { images are improved based on } \\
\text { probability density function. }\end{array}$ & $\begin{array}{l}\text { Fails to preserve the } \\
\text { overall mean } \\
\text { brightness. }\end{array}$ \\
\hline $\begin{array}{l}\text { Averaging } \\
\text { Histogram } \\
\text { Equalization } \\
\text { (AVHEQ) [41] }\end{array}$ & $\begin{array}{l}\text { Helps in restoring } \\
\text { degradation while capturing. } \\
\text { Improves contrast, helps in } \\
\text { obtaining the dual objectives. } \\
\text { An averaging threshold } \tau \text { is } \\
\text { adopted and the efficient } \\
\text { golden section search } \\
\text { algorithm is introduced. }\end{array}$ & $\begin{array}{l}\text { Involves 1) Stretching the } \\
\text { color channel 2) Histogram } \\
\text { averaging 3) Histogram } \\
\text { Remapping. After stretching, } \\
\text { information is increased based } \\
\text { on combination of a } \\
\text { weighted-sum manner. } \\
\text { Weighted histogram is } \\
\text { normalized ensuring number } \\
\text { of pixels are equal to the total } \\
\text { sum of bins. }\end{array}$ & $\begin{array}{l}\text { The mean contrast of } \\
\text { some images was not } \\
\text { well preserved when } \\
\text { compared to other } \\
\text { techniques as per the } \\
\text { experiment. }\end{array}$ \\
\hline
\end{tabular}

Later most of the research work was held on a concept of histogram clipping (limiting the enhancement rate). Various techniques evolved with the above concept, with clipping the histogram by a limit based on some clipping process. The below Table 2 describes techniques based on the histogram clipping avoiding over enhancements and reducing domination effects, yielding better image details in the resultant image.

Table 2. Describes Histogram Equalization Techniques Based on Histogram Clipping

\begin{tabular}{|c|c|c|c|}
\hline $\begin{array}{c}\text { Author and Technique } \\
\text { Used }\end{array}$ & Research Focus & Proposed Solution & Limitation \\
\hline $\begin{array}{l}\text { Bi Histogram Equalization } \\
\text { median Plateau Limit } \\
\text { (BHEPL-D) [2] }\end{array}$ & $\begin{array}{l}\text { A similar technique to } \\
\text { BHEPL [62] }\end{array}$ & $\begin{array}{l}\text { Each sub image histogram is } \\
\text { clipped by median intensity } \\
\text { occurrences instead of mean } \\
\text { intensity in the sub- } \\
\text { histogram as a clipping } \\
\text { limit. }\end{array}$ & $\begin{array}{l}\text { Neglects } \\
\text { redistribution } \\
\text { process that } \\
\text { simplifies } \\
\text { computation. }\end{array}$ \\
\hline $\begin{array}{l}\text { Dynamic } \\
\text { histogram quadrants } \\
\text { plateau limit(DQHEPL) [2] }\end{array}$ & $\begin{array}{l}\text { Median intensity } \\
\text { value is used as a } \\
\text { divisor. Histograms } \\
\text { are recursively } \\
\text { divided into four sub } \\
\text { parts. }\end{array}$ & $\begin{array}{l}\text { Clips individual sub parts } \\
\text { with a clipping process } \\
\text { using mean intensities with } \\
\text { maintained separation point } \\
\text { at the first recursive level. } \\
\text { Finally HE is applied } \\
\text { separately }\end{array}$ & $\begin{array}{l}\text { This method distorts } \\
\text { the fine details of } \\
\text { the image. }\end{array}$ \\
\hline
\end{tabular}




\begin{tabular}{|c|c|c|c|}
\hline $\begin{array}{c}\text { Author and Technique } \\
\text { Used }\end{array}$ & Research Focus & Proposed Solution & Limitation \\
\hline $\begin{array}{l}\text { Range Limited Bi-Histogram } \\
\text { Equalization (RLBHE) [19] }\end{array}$ & $\begin{array}{l}\text { Image Histogram } \\
\text { threshold is } \\
\text { automatically } \\
\text { calculated using } \\
\text { Otsu's method - } \\
\text { minimizes the intra- } \\
\text { class variance. }\end{array}$ & $\begin{array}{l}\text { Involves histogram } \\
\text { separation by choosing a } \\
\text { proper threshold between } \\
\text { plane and background } \\
\text { separates and equalizes the } \\
\text { target region and high level } \\
\text { background yielding } \\
\text { minimum AMBE. }\end{array}$ & $\begin{array}{l}\text { Unable to preserve } \\
\text { Mean brightness. } \\
\text { Do not accurately } \\
\text { perform well with } \\
\text { single threshold for } \\
\text { complex scenes }\end{array}$ \\
\hline $\begin{array}{l}\text { Composed of Automatic } \\
\text { Histogram Separation } \\
\text { module and an intensity } \\
\text { transformation module [21] }\end{array}$ & $\begin{array}{l}\text { Image is enhanced } \\
\text { using transformation } \\
\text { mapping function. }\end{array}$ & $\begin{array}{l}\text { Involves identifying multiple } \\
\text { thresholds, selected based on } \\
\text { the mean and } \sigma \text {, with three } \\
\text { thresholds } \mu-\sigma, \mu \text { and } \mu+\sigma \text {. }\end{array}$ & $\begin{array}{l}\text { Computational cost } \\
\text { of calculating } \\
\text { thresholds. }\end{array}$ \\
\hline $\begin{array}{l}\text { Exposure based Sub Image } \\
\text { Histogram Equalization } \\
\text { (ESIHE) [28] }\end{array}$ & $\begin{array}{lrr}\text { Considers } & \text { under } \\
\text { exposed part } & \text { (low } \\
\text { exposure } & \text { intensity } \\
\text { bins). The } & \text { clipped } \\
\text { histogram is } & \text { divided } \\
\text { based on } & \text { the } \\
\text { threshold. } & & \end{array}$ & $\begin{array}{l}\text { Based on exposed intensity } \\
\text { measure - an exposure } \\
\text { threshold parameter is } \\
\text { defined, divides the } \\
\text { histogram into under } \\
\text { exposed and over exposed } \\
\text { sub histograms based on the } \\
\text { Clipping Threshold. }\end{array}$ & $\begin{array}{l}\text { Best suited only for } \\
\text { under } \quad \text { exposed } \\
\text { images. }\end{array}$ \\
\hline $\begin{array}{l}\text { Median - Mean based Sub } \\
\text { Image Clipped Histogram } \\
\text { Equalization (MMSICHE) } \\
{[29]}\end{array}$ & $\begin{array}{l}\text { The difference } \\
\text { observed is the mean } \\
\text { and median } \\
\text { calculations followed } \\
\text { by the clipped } \\
\text { threshold calculations } \\
\text { (median intensity } \\
\text { values). }\end{array}$ & $\begin{array}{l}\text { Input histogram is divided } \\
\text { using median intensity. Each } \\
\text { sub histograms are further } \\
\text { equally bi-parted with } \\
\text { individual's mean } \\
\text { calculated. Using the } \\
\text { transfer functions, all the } \\
\text { four histograms are } \\
\text { equalized integrated into one } \\
\text { complete resultant image. }\end{array}$ & $\begin{array}{l}\text { Restricts histogram } \\
\text { bins to either the } \\
\text { mean or median } \\
\text { values. }\end{array}$ \\
\hline $\begin{array}{l}\text { Segment } \quad \text { Dependent } \\
\text { Dynamic Multi-Histogram } \\
\text { Equalization(SSDMHE) } \\
{[30]}\end{array}$ & $\begin{array}{l}\text { Ensures the even } \\
\text { distribution of pixels } \\
\text { on each segment of } \\
\text { histogram, avoiding } \\
\text { intensity saturation } \\
\text { effects. }\end{array}$ & $\begin{array}{l}\text { Segmentation of the input } \\
\text { histogram is based on both } \\
\text { mean and median intensity } \\
\text { values namely SDDMHE-M } \\
\text { and SDDMHE-D. Only the } \\
\text { narrow segments are } \\
\text { expanded while un-altering } \\
\text { the other segments. }\end{array}$ & $\begin{array}{l}\text { It introduces } \\
\text { computational } \\
\text { complexity in terms } \\
\text { of cost }\end{array}$ \\
\hline $\begin{array}{l}\text { Segment Selective Dynamic } \\
\text { Histogram Equalization } \\
\text { (SSDHE) [31] }\end{array}$ & $\begin{array}{lr}\text { It equalizes } & \text { segments } \\
\text { having } & \text { high } \\
\text { probability } & \text { regions - } \\
\text { keeping } & \text { other } \\
\text { segments } & \text { normal. } \\
\text { Linear } & \text { scaling is }\end{array}$ & $\begin{array}{l}\text { Entire image histogram is } \\
\text { remapped to the full DR } \\
\text { forming new intensities. For } \\
\text { segments having un-even } \\
\text { intensities, a new DR is } \\
\text { allocated. The Desired }\end{array}$ & $\begin{array}{l}\text { The method } \\
\text { performs well only } \\
\text { with large number } \\
\text { of segments (n) as } \\
\text { per the experimental }\end{array}$ \\
\hline
\end{tabular}




\begin{tabular}{|c|c|c|c|}
\hline $\begin{array}{l}\text { Author and Technique } \\
\text { Used }\end{array}$ & Research Focus & Proposed Solution & Limitation \\
\hline & $\begin{array}{l}\text { adopted to avoid high } \\
\text { computation cost. }\end{array}$ & $\begin{array}{l}\text { image quality is achieved in } \\
\text { less time. }\end{array}$ & results. \\
\hline $\begin{array}{l}\text { Adaptive } \\
\text { Enhancement based on Bi- } \\
\text { Histogram Equalization with } \\
\text { clipping limit (AIEBHE) } \\
\text { [33] }\end{array}$ & $\begin{array}{l}\text { Flexible in choosing } \\
\text { the best clipping limit } \\
\text { criteria. Helps in } \\
\text { avoiding } r \text { over- } \\
\text { stretching rand } \\
\text { domination effect. }\end{array}$ & $\begin{array}{l}\text { Median value used as a } \\
\text { threshold. The clipping limit } \\
\text { used is the minimum among } \\
\text { the histogram bins (mean } \\
\text { and the median value). }\end{array}$ & $\begin{array}{l}\text { To be extended to } \\
\text { color images. } \\
\text { Currently limited to } \\
\text { cervical cell images. }\end{array}$ \\
\hline $\begin{array}{l}\text { Brightness Preserving } \\
\text { Weighted Dynamic Range } \\
\text { Histogram Equalization } \\
\text { (BPWRDRHE) [35] }\end{array}$ & $\begin{array}{l}\text { Histogram } \\
\text { separated based on } \\
\text { Otsu's method - } \\
\text { identifying separation } \\
\text { points using minimum } \\
\text { class of variance } \\
\text { forming sub- } \\
\text { histograms. }\end{array}$ & $\begin{array}{l}\text { HE is applied to each sub- } \\
\text { part independently. } \\
\text { Additional post-process step } \\
\text { is performed - smoothens } \\
\text { and normalizes the } \\
\text { histogram by correcting the } \\
\text { scattered input histogram } \\
\text { after HE. }\end{array}$ & $\begin{array}{l}\text { Additional step of } \\
\text { post-processing } \\
\text { introduces } \\
\text { computational cost } \\
\text { complexity. }\end{array}$ \\
\hline $\begin{array}{lr}\text { Recursive Exposure based } \\
\text { Sub Image Histogram } \\
\text { Equalization } & \text { (R-ESIHE) } \\
{[40]} & \end{array}$ & $\begin{array}{l}\text { An extension to } \\
\text { ESIHE [28] }\end{array}$ & $\begin{array}{l}\text { Recursively performs the } \\
\text { ESIHE method on the input } \\
\text { image with no of iterations } \\
\text { dependent on exposure } \\
\text { difference value (lesser than } \\
\text { a threshold) between } \\
\text { subsequent iterations. }\end{array}$ & $\begin{array}{l}\text { Do not yield good } \\
\text { results leading to } \\
\text { loss of fine image } \\
\text { details. }\end{array}$ \\
\hline $\begin{array}{l}\text { Recursively separated } \\
\text { Exposure based Sub Image } \\
\text { Histogram Equalization (RS- } \\
\text { ESIHE) [40] }\end{array}$ & $\begin{array}{l}\text { Avoids over/ } \\
\text { excessive } \\
\text { enhancements by } \\
\text { histogram clipping. } \\
\text { Yields good visual } \\
\text { quality contents. }\end{array}$ & $\begin{array}{l}\text { Input histogram is } \\
\text { decomposed only once } \\
\text { based on the exposure } \\
\text { threshold in ESIHE, whereas } \\
\text { in RS-ESIHE, the input } \\
\text { histogram is decomposed } \\
\text { recursively using exposure } \\
\text { thresholds until a recursive } \\
\text { level ' } r \text { ', leading to } 2^{\mathrm{r}} \text { sub- } \\
\text { parts. }\end{array}$ & $\begin{array}{l}\text { Involves } \\
\text { computational cost } \\
\text { in calculating the } \\
\text { exposure threshold } \\
\text { values. }\end{array}$ \\
\hline $\begin{array}{l}\text { Range limited double } \\
\text { threshold multi-Histogram } \\
\text { Equalization (RLDTMHE) } \\
{[41]}\end{array}$ & $\begin{array}{l}\text { Double-threshold } \\
\text { Otsu's method } \\
\text { calculates the } \\
\text { thresholds } \mathrm{T} 1 \text { and T2 }\end{array}$ & $\begin{array}{l}\text { Average variance is used } \\
\text { instead of mean values in } \\
\text { Otsu's method. Finally each } \\
\text { sub-image histogram is } \\
\text { independently equalized } \\
\text { forming the output image. }\end{array}$ & $\begin{array}{l}\text { Lacks information } \\
\text { in determining the } \\
\text { number of } \\
\text { thresholds. }\end{array}$ \\
\hline $\begin{array}{lr}\text { A new Adaptive } & \text { Contrast } \\
\text { Enhancement } & \text { using } \\
\text { Modified r Histogram } & \text { Equalization (ACMHE) [47] }\end{array}$ & $\begin{array}{l}\text { Input histogram } \\
\text { divided into four sub- } \\
\text { parts using Median } \\
\text { values. Histograms } \\
\text { are equalized with a } \\
\text { process controlling } \\
\text { Enhancement rate }\end{array}$ & 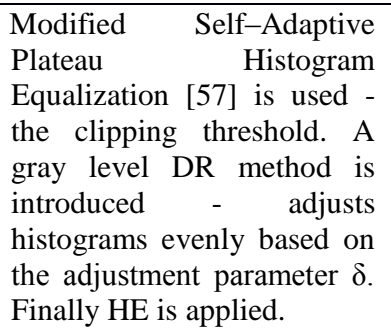 & $\begin{array}{l}\text { Noisy artifacts are } \\
\text { introduced. } \\
\text { Determining } \\
\text { enhancement rate is } \\
\text { quite hard. Can be } \\
\text { extended to color } \\
\text { images. }\end{array}$ \\
\hline
\end{tabular}

Each of the above techniques has experimental results based on Qualitative or Quantitative measurements in their base paper for different images. Qualitative analysis is 
held by evaluating the image enhancement results based on visual perception. Whereas Quantitative measure namely involves Discrete Entropy (DE), Peak-signal-to-noise ratio (PSNR), Absolute Mean Brightness Error (AMBE), Contrast Improvement Index (CII), Contrast per pixel (CPP), Computational time, Background grey levels (BGL), Fuzziness, Structural similarity index (SSI) and so on. A performance comparison of DE and AMBE values is carried out in Table 3 and 4.

Table 3. Performance Comparison of De Values of Tank, U2, Hands, Fish and Field Images for He, Esihe, Bhepl-D and Mmsiche Methods

\begin{tabular}{|c|c|c|c|c|c|}
\hline Image Name & Image Value (DE) & HE & BHEPL-D [2] & ESIHE [28] & MMSICHE [29] \\
\hline Tank & 5.49 & 4.97 & 2.91 & 5.47 & 5.50 \\
\hline U2 & 5.64 & 5.12 & 4.28 & 5.59 & 5.55 \\
\hline Hands & 3.99 & 2.89 & 3.97 & 3.92 & 3.98 \\
\hline Fish & 4.49 & 4.43 & - & 4.49 & 4.45 \\
\hline Field & 6.56 & 5.93 & 3.86 & 6.52 & 6.56 \\
\hline
\end{tabular}

Most of these techniques exhibit better DE but lacks in preserving mean brightness of images as shown in the Table 3 and 4. Each technique lacks in enhancing the images in one way or the other especially with respect to exhibiting maximum information content of the image or having better image visual quality as described in Table 1 and 2.

Table 4. Performance Comparison of Ambe Value of U2 Image for He, Bhepl-D, Mmsiche, Ssdmhe-M, Ssdmhe-D and Dqhepl Methods

\begin{tabular}{|c|c|c|c|c|c|c|c|}
\hline $\begin{array}{l}\text { Image } \\
\text { Name }\end{array}$ & Original & HE & $\begin{array}{c}\text { BHEPL-D } \\
{[2]}\end{array}$ & $\begin{array}{c}\text { MMSICHE } \\
{[29]}\end{array}$ & $\begin{array}{c}\text { SSDMHE - } \\
\text { M [30] }\end{array}$ & $\begin{array}{l}\text { SSDMHE - } \\
\text { D [30] }\end{array}$ & $\begin{array}{c}\text { DQHEPL } \\
{[2]}\end{array}$ \\
\hline $\mathrm{U} 2$ & 75.77 & 63.8809 & 26.40 & 4.64 & $\begin{array}{ll}\mathrm{n}=4, & 26.38 \\
\mathrm{n}=8, & 24.27 \\
\mathrm{n}=16, & 24.12 \\
\mathrm{n}=32, & 22.68\end{array}$ & $\begin{array}{ll}\mathrm{n}=4, & 26.26 \\
\mathrm{n}=8, & 23.25 \\
\mathrm{n}=16, & 22.69 \\
\mathrm{n}=32, & 22.13\end{array}$ & 29.34 \\
\hline
\end{tabular}

\section{Direct Contrast Enhancement Techniques}

Direct Contrast enhancement Techniques manipulates the image contrast directly. One of the key steps involved is establishing the image contrast measure. As the above traditional Indirect Contrast enhancement methods do exists with limitations in its use, recent trends of research are focused towards mathematical morphology for image Enhancement. Some morphological operations are well used to enhance or extract the useful information in small target regions. Basic operation normally includes erosion and dilation, opening and closing, boundary extraction, Top-hat and well transform and so on. These operations enhance the contrast between the light and dark regions of the image (not only small target regions). However due to the detail smoothing of morphological operations, sometimes the images may not be well enhanced. In order to suppress the detail smoothing effect, new tap-hat transform [6] was proposed. Also the extracted light and dark image regions may have different sizes and resolutions at different scales. In order to extract all the regions of interest, multiscale morphology (MSM)[48] was used to construct a pyramid from a single input image, reducing the image by various small factors resulting in a set of scaled images.

Based on the above analysis, a multiscale new Top-Hat transform (MSNTH) based algorithm [8] was proposed for Infrared image enhancement. Instead of using single structuring element, the multi-scale new top-hat transform algorithm used two different multi-scale structuring elements with increasing sizes for extracting regions of interest 
with different sizes at different scales. These extracted image regions provides more useful image features for infrared Image enhancement. But because of the usage of multiscale structuring elements, drawback with real time application is that the algorithm runs slowly with poor performance.

In order to utilize the image features efficiently, an algorithm was proposed which uses the pixels based on the saliency detection [22] and multiscale edge preserving decomposition [23]. Each pixel is given different weights by salient feature extraction process under frequency tuned idea. But Global based saliency feature extraction leads to uncertainty under different conditions. Hence local based saliency feature extraction is operated on Infrared images. Using Multiscale decomposition various frequency components at different scales are extracted. But this involves huge computational time as the saliency feature map is normally obtained by moving the local window over the entire image pixel-by-pixel. Also these methods are well suited for grey scale images.

One of the methods to extract the structural features of the original image is through SVD [27], [46]to preserve the mean brightness of the image. SVD of an image is normally represented in a matrix form, forming singular value matrix, providing the intensity information of the given image. Any change made to the value in the matrix, changes its corresponding intensity values. The method can produce good contrast over the enhanced image but constructing the database for future usage is the toughest part. And also its computational time is large for reducing the noise present in the image.

Furthermore, researchers focused on extension to the usage of Morphological operators. The extracted image details from Morphological operators may be smoothed and atmospheric effect of the algorithm may affect the performance. Later some research trend moved towards usage of toggle operator [49] - one of the useful morphological operators for identifying the fine details of the image. In Addition, the toggle operator using the opening and closing primitives [38]was redefined for extracting the image details. Multiscale feature extraction was carried out by sequential toggle operator resulting in smoothed bright and dim image features. The pixel wise comparing strategy [6], [8], [49] has been considered an effective way of feature extraction representing the fine details of image. The pixel wise extracted bright features are combined together for all scales forming multiscale image feature extraction. Moreover the extracted features usually have large grey values. Using the above Morphological operators, the bright image details are very well extracted and enhanced.

Later with few decades of research on Image contrast enhancement, continuing with Evolutionary like Genetic Algorithm (GA), Simulated Annealing (SA), Ant Colony Optimization (ACO) and Artificial Bee Colony (ABC) are used in Image enhancement. Recently hybridization of above methods has received very great interest. GA is an evolutionary global search method. The process of GA normally starts from a randomly generated individual of population and involves an iterative process. Each iteration with the population is called generation. For each new population, a pair of parent is selected and the children are produced through the recombination process (through the crossover and mutation). The newly acquired candidates will replace individuals in the population forming new generation and are used in the next iteration. In each generation, the fitness of each individual is evaluated within a fitness function. The worst individual and weaker parent in each generation are replaced with two new children. Removing the worst and weaker parent guaranties the survival of the fittest. Overall new generation of grey levels from GA [5] offers better contrast enhancement.

This helped researchers motivated towards the other evolutionary methods of soft computing techniques like the Particle swarm optimization (PSO) [58] based algorithms for better performance exhibiting computational simplicity with entropy gain. Image color correction and enhancement [16] was simultaneously proposed using PSO. Also Multiobjective Histogram Equalization (MOHE) method [32] evolved with usage of PSO. The main advantage observed in PSO is the time it takes to converge for better optima values 
is very less. Concept of PSO is that it uses particles (number of objects) that constitute a swarm which moves around in a particular search area looking for a best optimal solution. Each particle has track to its corresponding co-ordinates in the search area and tries to change its position using its information like current position, current velocity, the distance between its current position to the best value it has found so far in it neighborhood and so on.

One such Swarm Intelligent based methods are the ACO [50] and ABC [51] methods which describes the highly co-ordinate behavior of real ants. This helps in solving computational problems by exploiting, collaborating the behavior of ants seeking a path between the source of its food and their colony. While searching shortest paths, each ant deposits a substance called pheromone in the search area. More the amount of pheromone deposition indicates good results to decide and follow the path with high probability for the next ants. Based on the information concerned with different applications of Ant Colony system, the method is very limited to image processing and is mainly used in edge detection [7] and pose estimation [59]. Hence a new Artificial Ant Colony System (AACS) [10] was used to address the limitations of Image enhancement. Instead of using local min values, global min values were used and also as soon as the ant fails to find food for it, the ant dies thus reducing the complexity of the algorithm and helps faster processing. But complexity in selecting the parameters (no of ants, precision needed, no of cycles) is not standard for all applications and are difficult in arriving at an optimal solution in lesser time. Furthermore AACS was employed with fuzzy sets [10] to enhance the contrast of high dynamic range color images.

Simultaneously the concept of ABC [51] was proved to be an efficient way of solving optimization problems based on behavior of honey bees. The Bee colony algorithm is divided into 3 subgroups - Employed bees, Onlookers and Scouts. First the employed honey bee performs waggle dance when it finds new food sources and share its information to the onlookers. The Onlookers now selects good food sources among the ones found by the employed honey bees and finds a better food source searching around them. Similarly the artificial version of the bees behaves the same wherein the artificial bees fly in multidimensional search area and choose possible solutions of food sources. The employed bees and onlookers choose best solution between every pair of solutions while the Scouts tends to have a random search for new food sources and replace the most inactive solutions with a newly generated one. Thus a set of input grey levels are substituted by a new set offering better image quality. A new Artificial Bee colony [24] method was developed as an extension to the existing method for contrast enhancement. This method has limitation to apply other variants of $\mathrm{ABC}$ algorithm in solving issues related to enhancement and also involves future work in using HSV for color images.

Also Simulated Annealing mimics the process of Metallurgy annealing, normally involves controlled cooling of materials. Slow and controlled cooling makes the material (algorithm) less defective. Hence algorithm in each step has less chance in choosing bad solutions. Thus an efficient contrast image enhancement using Ant colony optimization, Genetic Algorithm and Simulated Annealing [17] was proposed. This method is fast with global transformation of intensities but since the usage of Evolutionary methods -GA, ACO and SA are slow and robust.

For low luminance images - a new histogram called gray level information histogram [11]is used to improve the histogram of X-ray images. Histograms having high gradients contains more detailed information (accurate estimation of its contribution) when compared to low gradient areas (usually the image background). The large background regions having high frequency components normally limits the contrast stretching of small (low frequency) image details thus resulting in washed-out appearance of the background. Hence the gray level histogram was developed. One of the problems observed with this method is to choose a value to divide the image into two equal sized sub regions. For large number of segments, it has a computational cost complexity. 
In some case transforms are efficient ways of color image enhancement. One of the methods well suited for multiscale edge based color image enhancement is through the contourlet transform [45]. The Contourlet framework captures salient features of the image such as edges, curves, lines and contours. One of the drawbacks observed in wavelet transform is the hard detection of high anisotropic elements based on their alignments in the image. Therefore contourlet transform gives better performance, providing good representations of input image salient features due to their directional property. This algorithm still lacks with theoretical explanations and the filters are still yet to be developed well. This is considered as a future work for improving the filter qualities and also must improve the contourlet transform.

There are many methods based on color space conversion. Usually color space conversion transforms RGB image to specific color space and performs image enhancement on luminance component and then, transformed back to RGB. They tend to normally cause color distortion. Hence an Overall Brightness and Local Contrast Adaptive Enhancement (OBLCAE) [34] method was proposed. It transforms the color image from RGB format to HSV color space to extract the $\mathrm{V}$ component value. The image details are to be highlighted more in the darker areas for low light images. Local contrast enhancement varies in different luminance areas and hence a non-linear adjustment of local contrast is calculated based on the local brightness. This method is not suitable for very low luminance images due to the defects observed in the non-linear mapping function.

Although there are tremendous techniques in enhancing the contrast, most of them concentrated on utilizing the image intensity information without emphasizing the exact change in intensity. Moreover the HVS is very sensitive to intensity changes (gradient) rather than the absolute image intensities. Hence variational infrared image enhancement algorithm based on gradient field equalization [36] was introduced to enhance the gradients specifically with adaptive dual thresholds. The gradients of each pixel in the image form a vector field named as gradient field. The histogram is calculated based on gradient values instead of gray level intensity values. In case of infrared images, the gradient values are small for most of them. Therefore histogram equalization just tends only to enhance the image (high probability details) whereas Gradient Histogram Equalization enhances the fine edge details of the image. Since the equally distributed gray levels in the histogram excessively extends/enlarges the DR when applied with gradient histogram Equalization - white spots are observed in the enhanced image due to over enhancement. To overcome the above problem, two adaptive thresholds are used. One of the drawbacks observed is the selection of adaptive thresholds based on the infrared images. Sometimes the threshold values selected may either over enhance or under enhance the images.

A novel Advanced Gradient Histogram Equalization (AGHE) method [42] was proposed to exhibit the image details at particular intensity levels. Traditional histogram methods only combined the pixel population count with intensity information but AGHE contains both gray scale intensity information and the corresponding scalar gradient value. One of the advantages observed in AGHE is that the peaks are smoothened since every pixel contributes to an intensity range in the image unlike the traditional histogram having high peaks tending to over enhance the contrast of the image. Hence optimal values are manually chosen for each image in order to achieve the best quality.

Several types of conventional enhancement methods are discussed with different working principles in nature. Adaptive trilateral contrast enhancement method (ATCE) is one of novel approach proposed [44], considering trilateral image characteristics namely contrast, intensity and sharpness. In ATCE, two plateau thresholds are used 1) Upper plateau threshold used to reduce over enhancement and noisy artifacts 2) Lower plateau threshold to prevent delicate input image details from overwhelming due to drastic change gain. This method results with an overhead of computational cost. 
Most of these image enhancement methods are not robust as each approach is geared to handle images degraded at particular level types. Also the application of RGB values to color image enhancement are inappropriate at certain cases and a kind of fuzzy in nature for human visual system. Hence fuzzy sets [53] were used as a problem solving tool between the classical mathematical and real world precision variables like contrast, boundaries, color and so on. There exist limitations in use of these methods as it is always hard to know how the environment in real circumstances renders its use. Hence Fuzzy logic was introduced.

Recent studies have investigated that Fuzzy logic based methods results in better output compared to traditional methods on Image enhancement. A fast and an efficient color image enhancement method using fuzzy logic [26] was proposed in which the V component of the histogram is stretched under the control of two parameters, average intensity value $(\mathrm{M})$ and contrast intensification parameter $(\mathrm{K})$. The main power of Fuzzy logic in image processing is the usage of appropriate fuzzy techniques like Fuzzy clustering, Fuzzy rule based approach, Fuzzy segmentation, Fuzzy thresholding, Fuzzy integration and so on. The most common operator is the INT operator (Intensification operator) which is applied globally in modifying the membership values and helps increasing the contrast of images. But this method completely depends on the membership function and is continuously applied until the required contrast is obtained. This limitation was improved using NINT [54] operator which uses Gaussian type fuzzification.

Recent studies have stressed towards the importance of fuzzy based contrast enhancement methods with usage of fuzzy hyperbolization, Equalization using fuzzy logic, Fuzzy edge based detection and segmentation (membership function based and rule based), Noise reduction using fuzzy filtering and so on. In addition, fuzzy sets came into existence as an extension to ordinary set theory. In fuzzy sets, basic operators are the Tnorm (intersection) and T-co-norm (union). The usage of Type I and Type II fuzzy sets were introduced to solve real world problems. Since the membership functions are fuzzy in nature and lies in an interval range, these uncertainties are represented in a better way with an advanced image enhancement method using Type II fuzzy set [25]. It uses the Hamacher T-co-norm to form new upper and lower membership functions. As medical images contain a lot of uncertainties Type II fuzzy sets are used as a very good tool for analyzing medical images. But addressing the color constancy is also a challenge.

To overcome the above limitation, a method using fuzzy rule based reasoning [37] helps in addressing two main problems namely color constancy and color enhancement simultaneously. The fuzzy rule based system operates on selecting the required color constancy algorithm from the three algorithms namely white patch, Gray-world and Gray edge algorithms. These algorithms are considered because of their accurate outstanding color and luminance enhancement. The design of fuzzy rule based system involves modeling a decision process through simple rules by considering several features like colors, texture descriptors, light and so on. Thus for any test image in this method, an appropriate color constancy algorithm is selected according to an inference process using Mamdani [55] and Larsen fuzzy inferences [56] and fuzzy rules are applied (which are determined from a subset of training images). As future work - Image features are to be evaluated and an automatic fuzzy rule-based selector is to be implemented, for usage in engineering applications in fields of interests like mobile phones, video surveillance systems, and security systems and so on.

\section{Comparisons between the Techniques}

Most of the conventional HE method described in this paper suffers from over enhancement and noisy artifacts with less exposure to details present in bright and dark regions. This paper focuses on describing many Direct and In-Direct contrast enhancement methods based on the usage of HE. In-Direct contrast enhancement methods 
modify the histograms by dividing the input image into segments using thresholds as described in table 1. Most of the techniques like the MHE [9], BPDFHQ [12] and BBPHE [14] address the issues related to over enhancement and preserving mean brightness of the images. But few of the methods like DRSHE [15], AGCWD [20] still lacks in reducing block noise and partially enhance fine details of the image resulting in high computational cost. Also few techniques like AHEA [13] are only applicable to CT image processing in medicine. Later various techniques evolved with the concept of histogram clipping as described in table 2 . These techniques started to clip the histogram by a limit based on the clipping process to address the image enhancement problems.

The main focus was to preserve the mean brightness with better image quality. Methods like RLBHE [19], AIEBHE [33] and BPWRDRHE [35] resulted in better image quality and increased feature information but with an overhead of computational cost of calculating thresholds. To avoid high computational cost of algorithm complexity, linear scaling [31] was adopted. Also Authors Kuldeep Singh and Rajiv Kapoor proposed methods ESIHE [28], MMSICHE [29], R-ESIHE and RS-ESIHE [40]are well suited only for under exposed images. Most of the above methods are to be extended to color images.

As the above In-Direct contrast enhancement methods do exists with limitations in its use, recent trends of research are focused towards direct contrast enhancement methods. One such method is the usage of mathematic morphological operations. These operations enhance the contrast between the light and dark regions of the image. Furthermore, researchers focused on extension to the usage of Morphological operations. The extracted light and dark image regions may have different sizes and resolutions at different scales. In order to extract all the regions of interest, multiscaling came into existence. One of the drawbacks observed with multiscaling in real time application is that the algorithm runs slowly with poor performance. Salient feature detection prominently added value to image contrast enhancement.

In order to utilize the image features efficiently, an algorithm was proposed which uses pixels based on the saliency detection [22] and multiscale edge preserving decomposition [23]. Also SVD is used to extract the structural features of the original image [27] and preserve the mean brightness of the image [46]. Reducing the noise present in the image is difficult and the methods are time consuming.

Later with few decades of research on Image contrast enhancement, continuing with Evolutionary techniques like GA, SA, ACO and ABC are used in Image enhancement. Recently hybridization of above methods has received very great interest as discussed in Section IV. This helped researchers motivated towards the other evolutionary methods of soft computing techniques like PSO based algorithms for better performance. Image enhancement with PSO leads to overburden on each particle to have track on its corresponding co-ordinates in the search area. Also Enhancing images with wavelet transform normally results in tiling distortion observed in the output image. One of the methods well suited for multiscale edge based color image enhancement is through the contourlet transform. Few algorithms still lacks with theoretical explanations on usage of filters. This is considered as a future work for improving the filter qualities and also must improve the usage of contourlet transform.

There are many methods based on color space conversion. They tend to normally cause color distortion. Moreover the HVS is very sensitive to intensity changes (gradient) rather than the absolute image intensities. Histogram equalization just tends only to enhance the image (high probability details) whereas Gradient Histogram Equalization enhances the fine edge details of the image. Hence the concept Gradient histogram equalization [36], [42] was utilized in most of the research work. Most of these image enhancement methods are not robust as each approach is geared to handle images degraded at particular level types. In order to have a quantitative comparison, the linear index of fuzziness [53] is considered to compare the enhancement performance of the above discussed algorithms. The linear index of fuzziness measure denoted by $y$ is defined as below: 


$$
\begin{gathered}
\gamma(g)=\frac{2}{W H} \sum_{x=1}^{W} \sum_{y=1}^{H} \min \{p(x, y)(1-p(x, y))\} \\
p(x, y)=\sin \left[\frac{\pi}{2} \times\left(1-\frac{g(x, y)}{\max (g)}\right)\right]
\end{gathered}
$$

Where $g(x, y)$ represents the gray values of pixels $x$ and $y \cdot \max (f)$ represents the maximum gray value of the image $\mathrm{f}$. $\mathrm{W}$ and $\mathrm{H}$ are the width and height of the image $\mathrm{f}$. The smaller the fuzziness value $y$, the better the contrast enhancement algorithm performs.

Table 5 indicates the measure of linear index of fuzziness and their corresponding time complexities of the few techniques. With techniques using multiscale analysis, the calculated time as per the table 5 is much higher compared to the traditional HE methods. Because of multiscale structuring elements used in few algorithms, the time complexity to extract the multiscale regions at different scales is very high. Though the fuzziness value of the algorithm [38] based on Multiscale Sequential Toggle Operator using opening and closing primitives is best when compared to other techniques. The image details are very well enhanced and are very clear with respect to infrared images.

Table 5. Quantitative Comparison of Image Enhancement Using $Y$

\begin{tabular}{|c|c|c|c|c|c|c|c|}
\hline Original Image & HE & $\begin{array}{c}\text { CLAHE } \\
{[\mathbf{5 2}]}\end{array}$ & $\begin{array}{c}\text { MSM } \\
{[\mathbf{4 8}]}\end{array}$ & MSNTH & $\begin{array}{c}\text { Multiscale } \\
\text { Saliency } \\
{[\mathbf{8}]}\end{array}$ & $\begin{array}{c}\text { Multiscale } \\
\text { Sequential } \\
\text { Toggle } \\
\text { Operator } \\
{[\mathbf{3 8}]}\end{array}$ & $\begin{array}{c}\text { Type II } \\
\text { Fuzzy } \\
\text { Method } \\
{[\mathbf{2 5}]}\end{array}$ \\
\hline $\begin{array}{c}\text { Fuzziness } \\
\text { y(0.5314) }\end{array}$ & 0.39994 & 0.5713 & 0.3572 & 0.2224 & 0.3717 & 0.1987 & 0.1198 \\
\hline $\begin{array}{c}\text { Time } \\
\text { Complexity(s) }\end{array}$ & 0.134 & 0.192 & 2.110 & 54.032 & 0.094 & - & 0.5 \\
\hline
\end{tabular}

But one of the future works is to accelerate the algorithm as it uses multi-scale analysis and the time taken is huge for different images. Also the improved Type II Fuzzy method [25] yields better results for medical images with an overhead of time complexity. The Figure 2 below represents enhancement comparisons of few contrast enhancement techniques.
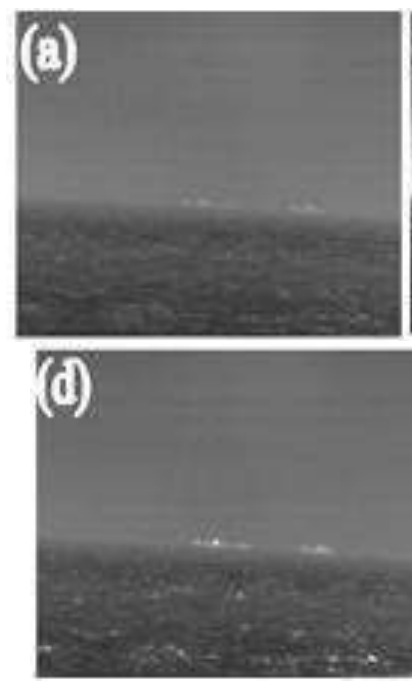
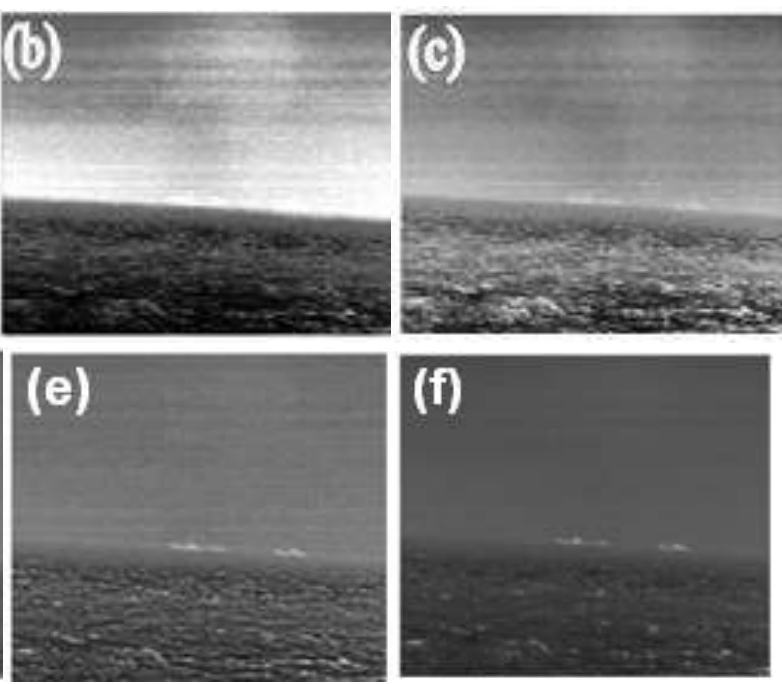


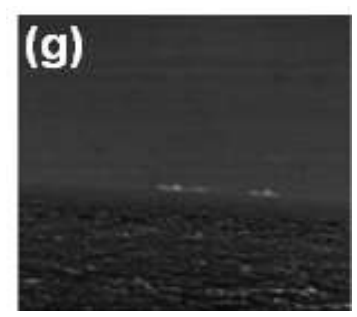

\section{Figure 2. Enhancement Result Comparison of a) Original Image b) HE c) CLAHE [52] d) Multiscale Saliency Extraction [23] Method e) MSM [48] f) MSNTH [8] Method g) Multiscale Sequential Toggle Operator [38] Method}

Hence Multiscale based morphological operations and Fuzzy Logic based methods have driven attraction in yielding better output compared to traditional methods of Image enhancement as discussed. Hence more research is to be focused on reducing the time complexities of these algorithms. Also image features play a vital role in Fuzzy logic. Hence as future work - An Automatic Fuzzy rule-based selector is to be implemented considering all the image features which are useful in engineering applications like mobile phones, video surveillance systems, and security systems and so on. Recent studies have stressed more towards the importance and necessity of identifying automatic methods of contrast enhancement. Hence a good research is to be carried out for enhancing color images automatically.

\section{Conclusion}

In this paper, a comparative survey is carried out describing various Direct and InDirect Contrast Image enhancement techniques with their advantages and disadvantages. Histogram Equalization acts as a base to most of the Image enhancement techniques. Most of these methods suffer with over enhancement and high saturation effects. Based on the comparison, extracting image features plays a vital role in image enhancements. Recent studies have driven attention towards certain edge preserving filters, Intelligent based swarm methods and Fuzzy logic methods in increasing the performance of Image enhancements based on the image features. All of these algorithms are intended to enhance the image contrast but each approach is geared to handle images degraded at particular intensity level types. Hence an active research is to be conducted for identifying an automatic contrast enhancement method for all types of images with reduced time complexity.

\section{References}

[1] R. C. Gonzalez and R. E. Woods, "Digital Image Processing ( $2^{\text {nd }}$ ed.)", Prentice Hall, (2002).

[2] C. H. Ooi and N. A. M. Isa, "Adaptive contrast enhancement methods with brightness preserving", IEEE Transactions on Consumer Electronics, IEEE Press Piscataway, NJ, USA, vol. 56, (2010), pp. 25432551.

[3] P. C. Wu, F. C. Cheng and Y. K. Chen, "A Weighting Mean Separated Sub-Histogram Equalization for Contrast Enhancement", Proceeding on International Conference Biomedical Engineering and Computer Science (ICBECS), Wuhan, (2010), pp.1-4.

[4] Y. C. Chang and C. M. Chang, "A simple histogram modification scheme for contrast enhancement", Consumer Electronics, IEEE Transactions, vol. 56, (2010), pp.737 - 742.

[5] S. Hashemi, S. Kiani, N. Noroozi abd M. E. Moghaddam, "An image contrast enhancement method based on genetic algorithm", Pattern Recognition Letters, Elsevier, vol. 31, no. 13, (2010), pp. 18161824.

[6] X.Bai and F. Zhou, "Analysis of new top-hat transformation and the application for infrared dim small target detection”, Pattern Recognition, Elsevier, vol. 43, no. 6, (2010), pp. 2145-2156.

[7] J. Zhang, K. He, J. Zhou and M. Gong, "Ant Colony Optimization and Statistical Estimation Approach to Image Edge Detection", 6th International Conference on Wireless Communications Networking and Mobile Computing (WiCOM) IEEE, (2010), pp. 1-4. 
[8] X. Bai, F. Zhou and B. Xue, "Infrared image enhancement through contrast enhancement by using multiscale new Top-Hat transform", Infrared Physics and Technology, Elsevier, vol. 54, (2011), pp. $61-$ 69.

[9] M. M. Naushad Ali and M. A. Al-Wadud, "Image Enhancement Using a Modified Histogram Equalization", Computer Applications for Web, Human Computer Interaction, Signal and Image Processing, and Pattern Recognition, Springer, vol. 342, (2011), pp.17-24.

[10] O. P. Varma, P. Kumar, M. Hanmandlu and S. Chhabra, "High dynamic range optimal fuzzy color image enhancement using Artificial Ant Colony system", Applied Soft Computing, Elsevier, vol. 12, (2012), pp. 394-404.

[11] Ming Zeng, Youfu Li, Qinghao Menga, Ting Yanga and Jian Liua, "Improving histogram-based image contrast enhancement using gray-level information histogram with application to X-ray images", Optik International Journal for Light and Electron Optics, Elsevier, Vol. 123, (2012), pp.511 - 520.

[12] Sheet D., Garud H., Suveer A., Chatterjee J. and Mahadevappa M., "Brightness preserving dynamic fuzzy histogram equalization", Consumer Electronics, IEEE Transactions, Vol. 56, (2012), pp. 2475 2480.

[13] Youlian Zhu and Cheng Huang, "An Adaptive Histogram Equalization Algorithm on the Image Gray Level Mapping”, International Conference on Solid State Devices and Materials Science, Macao, Elsevier, Vol. 25, (2012), pp.601-608.

[14] Tan T. L., Sim K.S. and Tso C.P., "Image enhancement using background brightness preserving histogram equalization", Electronics Letters, Vol. 48, (2012), pp. 155-157.

[15] Iwanami T., GOTO T. and Sakurai M., "An adaptive contrast enhancement using regional dynamic histogram equalization”, Consumer Electronics (ICCE), IEEE International Conference, Las Vegas, NV, (2012), pp.719- 722 .

[16] N.M Kwok, H. Y. Shi, Q. P. Ha, G. Fang, S.Y. Chen, X. Jai, "Simultaneous image color correction and enhancement using Particle swarm optimization", Engineering Applications of Artificial Intelligence, Elsevier, Vol. 26, (2013), pp. 2356 - 2371.

[17] PouryaHoseini, Mahrokh G. Shayesteh, "Efficient contrast enhancement of images using Hybrid Ant colony optimization, Genetic Algorithm and Simulated Annealing”, Digital Signal Processing, Elsevier, Vol. 23, (2013), pp.879- 893.

[18] ArturLoza, David R. Bull, Paul R. Hill and Alin M. Achim, "Automatic Contrast Enhancement of lowlight images based on local statistics of wavelet coefficients", Digital Signal Processing, Elsevier, Vol. 23, (2013), pp. 1856 - 1866.

[19] Chao Zuo, Qian Chen and Xiubao Sui, "Range Limited Bi-Histogram Equalization for image contrast enhancement”, Optik - International Journal for Light and Electron Optics, Elsevier, Vol. 124, (2013), pp. $425-431$.

[20] Shih-Chia Huang, Fan-Chieh Cheng and Yi-Sheng Chiu, "Efficient Contrast Enhancement Using Adaptive Gamma Correction with Weighting Distribution”, Image Processing, IEEE Transactions, Vol. 22, (2013), pp.1032 - 1041.

[21] Shih-Chia Huang and Chien-Hui Ych, "Image Contrast enhancement for preserving mean brightness without losing image features", Engineering Applications of Artificial Intelligence, Elsevier, Vol. 26, (2013), pp.1487 - 1492.

[22] JufengZhoa, Yueting Chen, Huajun Feng, Zhihai Xu, Qi Li, "Real-time automatic small target detection using saliency extraction and morphological theory", Optik - Laser Technology, Elsevier, Vol. 47, (2013), pp. 268-277.

[23] JufengZhoa, Yueting Chen, Huajun Feng, Zhihai Xu, Qi Li, "Fast image enhancement using multiscale saliency extraction in infrared imagery", Optik - International Journal for Light and Electron Optics, Elsevier, Vol. 125, (2014), pp.4039- 4042.

[24] AmerDrra and Amira Bouaziz, "An Artificial Bee colony method for contrast enhancement", Swarm and Evolutionary Computation, Elsevier, Vol. 16, (2014), pp. $69-84$.

[25] TamalikaChaira, “An improved medical image enhancement using Type II fuzzy set”, Applied Soft Computing, Elsevier, Vol. 25, (2014), pp. 293 - 308.

[26] G. Raju, Madhu S. Nair, "A fast and efficient color image enhancement method based on fuzzy logic and histogram", AEU - International Journal of Electronics and Communication, Elsevier, Vol. 68, (2014), pp. $237-243$.

[27] Chien-Cheng Chu, Chien-Chih Wang and Bernard C Jiang, "Development of an automatic image enhancement method using singular value decomposition for visual inspection", International Journal of Advanced Manufacturing Technology, Springer, Vol. 70, (2014), pp.679-688.

[28] Kuldeep Singh and Rajiv Kapoor, "Image enhancement using Exposure based Sub Image Histogram Equalization", Pattern Recognition Letters, Elsevier, Vol. 36, (2014a), pp.10 - 14.

[29] Kuldeep Singh and Rajiv Kapoor, "Image enhancement via Median-Mean Based Sub-Image-Clipped Histogram Equalization”, Optik - International Journal for Light and Electron Optics, Elsevier, Vol. 125, (2014b), pp.4646- 4651 .

[30] Mohammad Farhan Khanand Ekram Khan,AbbasiZ. A., "Segment dependent dynamic multi-histogram equalization for image contrast enhancement”, Digital Signal Processing, Elsevier, Vol. 25, (2014a), pp.189-223. 
[31] Mohammad Farhan Khanand Ekram Khan,AbbasiZ. A., "Segment selective dynamic histogram equalization for brightness preserving contrast enhancement of images", Optik - International Journal for Light and Electron Optics, Elsevier, Vol. 125, (2014b), pp.1385 - 1389.

[32] Shanmugavadivu P. and Balasubramanian K., "Particle swarm optimized multi objective histogram equalization for image enhancement”, Optics \& Laser Technology, Elsevier, Vol. 57, (2014), pp. 243 251.

[33] Jing Rui Tang and Nor Ashidi Mat Isa, "Adaptive Image Enhancement based on Bi-Histogram Equalization with a clipping limit”, Computers \& Electrical Engineering, Elsevier, Vol. 40, (2014), pp.89- 103.

[34] Zhigang Zhou, Nong Sang and Xinrong Hu, "Global brightness and local contrast adaptive enhancement for low illumination color image", Optik - International Journal for Light and Electron Optics, Elsevier, Vol. 125, (2014), pp.1795 - 1799.

[35] Thien Huynh-The,Ba-Vui Le,Sungyoung Lee,Thuong Le-Tienand Yongik Yoon, "Using weighted dynamic range for histogram equalization to improve the image contrast", EURASIP Journal on Image and Video Processing, Springer, Vol. 44, (2014).

[36] Wenda Zhao, Zhijun Xu, Jian Zhao, Fan Zhao and Xizhen Han, "Variational infrared image enhancement based on adaptive dual-threshold gradient field equalization", Infrared Physics \& Technology, Elsevier, Vol. 66, (2014), pp.152 - 159.

[37] Jonathan Ceapda-Negrete and Raul E. Sanchez-Yanez, "Automatic selection of color constancy algorithms for dark image enhancement by fuzzy rule-based reasoning", Applied Soft Computing, Elsevier, Vol. 28, (2015), pp. $1-10$.

[38] Xiangzhi Bai, "Morphological infrared image enhancement based on multiscale sequential toggle operator using the opening and closing as primitives", Infrared Physics and Technology, Elsevier, Vol. 68, (2015), pp. $143-51$.

[39] Ahmad Shahrizan Abdul Ghani and Nor Ashidi Mat Isa, "Enhancement of low quality underwater images through integrated global and local contrast correction", Applied Soft Computing, Elsevier, Vol. 37, (2015), pp. $332-344$.

[40] Kuldeep Singh,Rajiv Kapoorand Sanjeev Kr. Sinha "Enhancement of low Exposure Images via Recursive Histogram Equalization Algorithms", Optik - International Journal for Light and Electron Optics, Elsevier, Vol. 125, (2015), pp.1385 - 1389.

[41] Honglie Xu, Qian Chen, Chao Zuo, Chunhua Yang and Ning Liu, "Range limited double-thresholds multi-histogram equalization for image contrast enhancement", Optical Review, Springer, Vol. 22, (2015), pp.246-255.

[42] Lidong Huang,Wei Zhao,Zebin Sunand Jun Wang, "An advanced gradient histogram and its application for contrast and gradient enhancement”, Optik - International Journal for Light and Electron Optics, Elsevier, Vol. 31, (2015), pp.86-100.

[43] Lin S.C.F., Wong C.Y., Rahman M.A., Jiang G., Liu S., Ngaiming Kwok, Haiyan Shi,Ying-Hao Yuand Tonghai $\mathrm{Wu}$, "Image enhancement using the averaging histogram equalization (AVHEQ) approach for contrast improvement and brightness preservation", Computers \& Electrical Engineering, Elsevier, [Online] http://www.sciencedirect.com/science/article/pii/S0045790615002050, ( 2015).

[44] Lo Tzer Yuan, SimKokSwee and Tso Chih Ping, "Infrared image enhancement using adaptive trilateral contrast enhancement", Pattern Recognition Letters, Elsevier, Vol. 54, (2015), pp.103 - 108.

[45] MelkamuHunegnawAsmare, Vijanth S. Asirvadam, and Ahmad Fadzil M. Hani, "Image enhancement based on contourlet transform", Signal, Image and Video Processing, Springer, Vol. 9, (2015), pp.1679 $-1690$.

[46] Randa Atta and Rabab Farouk Abdel-Kader, "Brightness preserving based on singular value decomposition for image contrast enhancement", Optik - International Journal for Light and Electron Optics, Elsevier, Vol. 126, (2015), pp.799 - 803.

[47] SanthiK. and WahidaBanuR. S. D., "Adaptive contrast enhancement using modified histogram equalization", Optik - International Journal for Light and Electron Optics, Elsevier, Vol. 126, (2015), pp. $1809-1814$

[48] G. Matheron, "Random Sets and Integral Geometry", Wiley, New York, USA, (1975).

[49] P. Soille, "Morphological image analysis-principle and applications", Springer, Germany, (2003).

[50] M. Dorigo and T. Stützle, "Ant Colony Optimization”, MIT Press, Cambridge, MA, (2004).

[51] D. Karaboga and B. Basturk, "Artificial Bee Colony (ABC) Optimization Algorithm for Solving Constrained Optimization Problems", Foundations of Fuzzy Logic and Soft Computing, Springer, vol. 4529, pp. 789 - 798

[52] K. Zuiderveld, "Contrast Limited Adaptive Histogram Equalization (CLAHE)", Graphics Gems IV, Academic Press, (1994), pp.474-485.

[53] A. Kaufmann, "Introduction to the Theory of Fuzzy", Academic Press, (1975).

[54] M. Handmandlu, D. Jha and R. Sharma, "Color image enhancement using fuzzy intensification", Pattern Recognition Letters, Elsevier, vol. 24, (2004), pp. 81-87.

[55] E. H. Mamdani, "Advances in the linguistic synthesis of fuzzy controllers", International Journal of Man-Machine Studies, Elsevier, vol. 8, no. 6, (1976), pp. 669-678. 
[56] M. Jamshidi, N. Vadiee and T. Ross, "Fuzzy logic and control: Software and hardware applications", $2^{\text {nd }}$ edition, Prentice Hall, Englewood Cliffs, NJ, (1993).

[57] A. Raju, G. S. Dwarakish and D. V. Reddy, "Modified Self-Adaptive Plateau Histogram Equalization (M-SAPHE) with mean threshold for brightness preserving and contrast enhancement", Image Information Processing (ICIIP), IEEE, ISBN: 978-1-4673-6101-9, (2013).

[58] Kennedy and Eberhart, “A New Optimizer using Particle swarm optimization”, (1995).

[59] S. Meshoul and M. Batouche, "Ant colony system with external dynamics for point matching and pose estimation", Proceeding of the 16th International Conference on Pattern Recognition, vol. 3, (2002), pp. 823-826.

[60] C. HeeOoi, N. S. P. Kong, and H. Ibrahim, "Bi-histogram equalization with a plateau limit for digital image enhancement”, Consumer Electronics, IEEE Transactions, vol. 55, (2009), pp. 2072 - 2080.

[61] G. H. Park, H. H. Cho and M. R. Choi, "A contrast enhancement method using dynamic range separate histogram equalization”, Consumer Electronics, IEEE Transactions, vol. 54, (2008), pp.1981 - 1987.

[62] C. H. Ooi, N. S. P. Kong, N.S.P. and H. Ibrahim, "Bi-histogram equalization with a plateau limit for digital image enhancement”, Consumer Electronics, IEEE Transactions, vol. 55, (2009), pp. 2072 2080 .

\section{Authors}

S. Supriya, is a Research Scholar in the School of Computer Science and Engineering Department, VIT University, Vellore. She received her Master's degree in Computer Science and Engineering, in 2013 from VIT University, Vellore. Her current research interests are Computer Networks (wireless Networks), Operating systems, Digital Image Processing, etc.

M. Subaji, obtained his Bachelor's degree in Mechanical Engineering from Manonmaniam Sundaranar University, Master's degree in Business Administration [specialization in Marketing] from University of Madras and $\mathrm{PhD}$ in Management Information Systems from Kookmin University, Korea. He is working as Professor at VIT University since September 2000 and his current research interests are Model Integrated Computing, Distributed Systems, Data Mining, Big Data Analytics. 
International Journal of Signal Processing, Image Processing and Pattern Recognition Vol. 10, No. 7 (2017) 